\title{
Preparing Faculty to Teach Online: Recommendations for Developing Self-Paced Training
}

\author{
Jason Rhode and Murali Krishnamurthi
}

\begin{abstract}
As the popularity of online education increases and institutions seek to grow their online offerings to meet student demand, more faculty need to be trained to teach online. Campus offices such as Faculty Development centers are often tasked with training faculty for teaching online, many of whom my be adjuncts who cannot attend in-person training or commit to a specific timeframe for participation. In this paper, a flexible and customizable self-paced training model for preparing faculty to teach online is described and suggestions shared for institutions seeking to offer self-paced online professional development training opportunities for faculty.
\end{abstract}

Index Terms-Faculty development, online teaching, self-paced training.

\section{INTRODUCTION}

Faculty Development centers or Teaching and Learning centers are responsible for supporting teaching excellence at their respective institutions and these efforts have traditionally been focused on advancing face-to-face teaching and learning. As new blended and online delivery modalities have emerged, the training and support for faculty likewise have grown and evolved to meet the full spectrum of current faculty needs [1]-[3]. In recent years, online teaching and learning have become widely accepted and an increasing percentage of postsecondary students are choosing to enroll in online courses and programs [4], [5]. This growing demand has been met by an ever-increasing number of institutions who have ventured to offer new online educational opportunities for students [6]. The online educational ecosystem is however drastically different from the traditional face-to-face classroom teaching and learning environment that is familiar to faculty in general.

The growth in the student demand as well as increased interest by institutions in offering online teaching and learning has prompted the need for faculty training for teaching online. While many educators with experience in the brick-and-mortar classroom are eager to tap into the successes of online teaching and learning, very few know where to begin A gap often exists between the intricacies of online learning and how educators can teach and facilitate effectively in this environment in order to enable student-centered teaching

Manuscript received September 15, 2014; revised December 1, 2014 This work was made possible in part by the Northern Illinois University Foundation Venture Grant.

J. Rhode is with the Faculty Development and Instructional Design Center at Northern Illinois University, DeKalb, IL 60115 USA (e-mail: jrhode@niu.edu).

M. Krishnamurthi is with the Office of the Provost and Department of Industrial \& Systems Engineering at Northern Illinois University, DeKalb, IL 60115 USA (e-mail: mkrishna@niu.edu). methods. Thus, a structured faculty development program on online teaching can assist in bridging this gap and provide educators the necessary online learning experience and pedagogical expertise to teach and communicate effectively in the online learning environment.

Before faculty can begin to hone their pedagogical and technical skills necessary to teach online, they need to possess foundational understanding of the tenets of online teaching and learning, including topics such as: overview of online teaching and learning, models of online course delivery, designing an online course, encouraging communication, technology tools for online teaching, and assessing student learning online [7], [8]. In addition, faculty need to be introduced to quality standards for online course design and delivery as well as available campus resources and services available in support of online instruction [9].

Faculty Development centers have employed a variety of delivery modalities for online teaching training and support. [10]. Instructor-led face-to-face and hybrid faculty development programs are common, in which faculty participants attend scheduled professional development sessions and participate in online learning activities [11]. Some institutions have developed fully-online professional development and online teaching certification programs that require faculty to complete specified activities and engage in online collaborations designed to model online teaching and learning best practices [12]. These approaches require significant time and resources, create scheduling constraints on faculty participants, and can be difficult to scale for larger groups.

Professionally-developed online training programs do exist, offered by professional organizations devoted quality online education, that institutions license and adopt instead of developing their own training. The Online Learning Consortium [13], Learning Resources Network [14], and Illinois Online Network [15] are just a few of the organizations that offer systematic online professional development programs for faculty teaching online. Additionally, institutions such as the University of Wisconsin-Madison [16] and University of Michigan-Flint [17] have developed certification programs that are available for faculty from outside their institution to enroll in and complete, for a fee.

While it may seem advantageous to simply license an existing third-party's online training program, many significant benefits to do exist for developing institution-specific training for faculty teaching online. Faculty training programs can be customized to specialized needs of the faculty teaching in a particular discipline and address specific online program needs. Institution-developed 
faculty training can also incorporate technology skill development on institution-specific learning management system tools and processes. Institutional online course and program development procedures and protocols can be addressed, including institution-specific branding and course quality standards.

Self-paced models for online training offer many attractive benefits and have been effectively implemented in a variety of online training contexts [18]-[20]. Self-paced training is time and place agnostic and typically characterized by learning activities that participants can engage in at an individual pace as well as customize to their personal needs. Participants can advance more quickly through information and activities they are already comfortable with, while spending additional time and effort on new or more challenging concepts. They can also choose to interact in the format and frequency that best meets their needs and aids them in connecting the concepts to practice. A self-paced learning experience, therefore, affords learners an increased measure of flexibility and autonomy that adult learners in particular enjoy.

\section{REASONS FOR SELF-PACED TRAINING OPPORTUNITIES}

A variety of reasons exist for embracing self-paced training opportunities, especially in supporting faculty interested in teaching online. The self-paced model for offering introductory information accommodates faculty who cannot attend in-person or commit to a specific timeframe for participation. Academic units with considerable student demand for online courses often rely on adjunct faculty to teach online courses, but those adjunct faculty members may not be on campus to be able to attend training programs. Adjunct faculty often also find it difficult to commit to training programs on fixed schedules offered online.

Self-paced training also accommodates varied participation and completion schedules. Faculty who want to get started quickly teaching online and perhaps expedite the training process can accelerate their learning. This completion flexibility is also advantageous to departments, schools, and administration as new faculty can be trained immediately upon hiring instead of having to wait until the next scheduled training session.

Additionally, those with varied teaching and technology expertise can begin with the self-paced training and then receive follow-up assistance for individualized and course-specific needs. Rather than taking all faculty participants through the same prescribed series of online activities and experiences, faculty can access and view the requisite information and self-select the follow-up support needed. This allows for more personalized and targeted consultations between support personnel and faculty.

Furthermore, since self-paced training is electronically delivered, it can be easily scaled to accommodate more faculty participants quickly than traditional instructor-led training. Institutions seeking to grow online course and degree program offerings often must expand their ranks of faculty trained on online teaching. As new faculty are hired by the institution, including adjunct instructors who may be bi-vocational and working other full-time jobs, faculty training efforts need to be flexible and customizable to meet the individualized needs of the faculty. The self-paced training option provides a robust and yet flexible solution.

\section{ConcePtualizing A SElf-PACED Training MODEL}

In order to meet the strategic planning goals of Northern Illinois University (NIU) to offer significantly more online courses and online degree programs, the Faculty Development and Instructional Design Center (FDIDC) set out to design a flexible and customizable online teaching training process that would accommodate the needs of faculty interested in gaining more experience in the principles and practices of online teaching. While FDIDC has previously offered training programs and workshops on online teaching, many faculty found it difficult to attend these programs during the academic semester. Recognizing that some faculty have previous exposure to online learning environments, it was envisioned that prospective online faculty be able to complete a series of structure, highly interactive and engaging activities that would expose them to various instructional strategies and successful online teaching models.

A self-paced training model was visualized (see Fig. 1), involving a consistent and sequential set of activities to be included, providing participants the opportunity to be exposed to new information as well as the flexibility of choosing the level of desired engagement and interaction. This model for self-paced training extends beyond participants mere viewing recorded materials, to encourage further exploration, application, and reflection. This self-paced training model is one framework that can be used for designing a variety of self-guided and individualized professional development experiences for faculty.

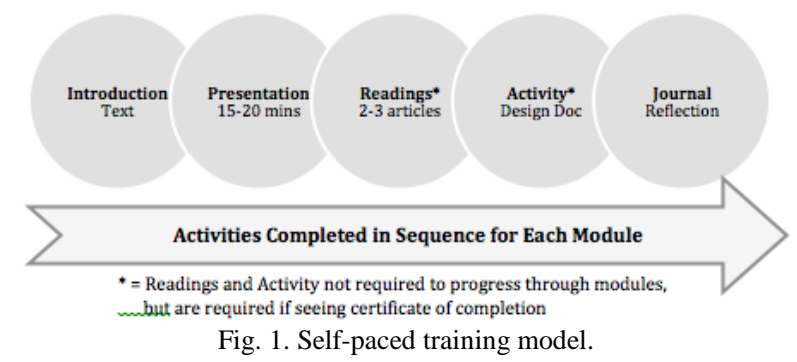

The project to be further described in this paper resulted in a set of interactive self-paced learning modules on online teaching, structured and offered in the form of a self-paced course that faculty can use to learn at their own pace and schedule. The composition and development of this self-paced online faculty development course will be described and suggestions shared for institutions seeking to offer similar self-paced professional development training opportunities for faculty.

\section{A. Topics}

After recognizing the aforementioned benefits to the self-paced modality for training faculty to teach online and conducting a through needs analysis, the project team identified the following six core topics to be addressed in sequence through the envisioned self-paced modules:

1) Overview of Online Teaching and Learning 
2) Models of Online Course Delivery

3) Designing an Online Course

4) Encouraging Communication in Online Courses

5) Technology Tools for Online Teaching

6) Assessing Student Learning Online

\section{B. Timeline and Milestones}

The project team met in early February 2012 to begin conceptualizing the goals and benefits of the self-paced modules. Over the following four-month period, the modules were scoped and sequenced, presentations scripted, activities designed, and the project plan reviewed by other FDIDC staff members for feedback. Other project phases followed over the ensuing twelve months included the development, review, implementation, and evaluation tasks. Financial support from the NIU Foundation Venture Grant made it possible for a graduate research assistant to be hired for twelve months to assist specifically with the design and development tasks.

\section{Module Structure}

The resulting modules, collectively referred to as "Preparing to Teach Online" were based on the current online teaching training offered by FDIDC and are similar to training programs on online teaching offered by the Online Learning Consortium, Illinois Online Network, and other nationally recognized external providers. Each module (see Fig. 2) was designed to include a visually appealing and easily navigable self-running instructional presentation, supplemental resources such as additional readings, a course design document activity, and a self-assessment. Individual faculty may spend anywhere between two to three hours or more on each module depending on their teaching and technology experience and expertise.
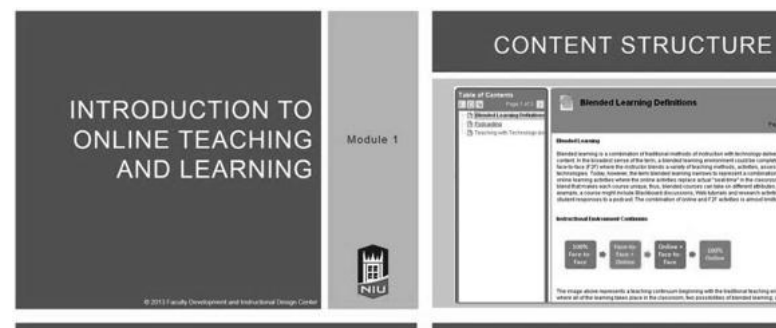

CONTENT DELIVERY
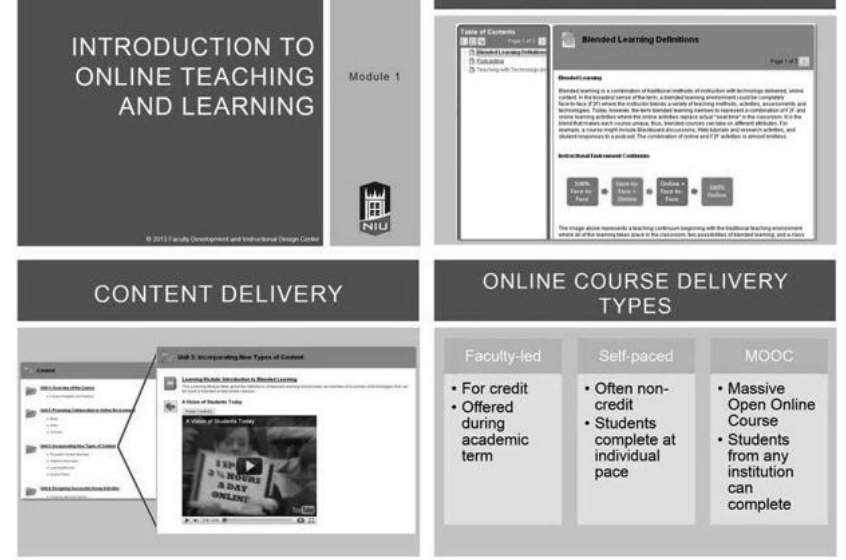

Fig. 2. Screenshots of a sample module presentation.

\section{Components}

In an effort to promote sound instructional design principles, the modules were embedded in an online course within the Blackboard learning management system. The Blackboard course (see Fig. 3) allowed the modules to be hosted securely within the university's online environment and made them easily accessible to all participants.

The course was specifically structured to be self-paced, in which the participants could work through each module at their leisure. The self-paced nature of the course meant that the course would not be actively facilitated and would not require any assignments to be submitted. Being primarily introductory and informational in nature, the modules were intended to provide faculty with the foundational tenets of online instruction, which could then be built upon through follow-up workshops or individualized consultations.

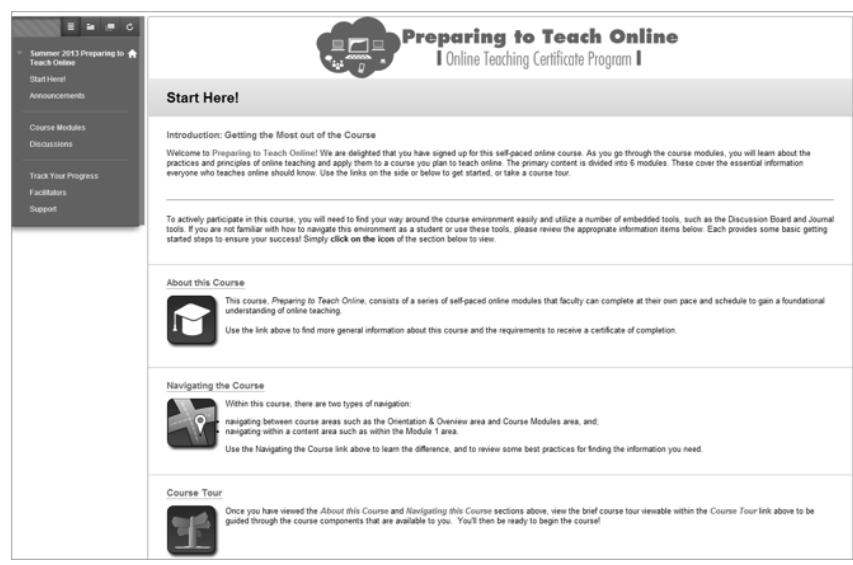

Fig. 3. Screenshot of Blackboard course containing self-paced modules.

The only major assessment in the course was an optional design document activity in which participants could scope and sequence their online course. This document was then submitted to the course facilitators at the conclusion of the course for feedback and review. Participants had the option to request a personalized consultation with a member of FDIDC to discuss the next steps of the course design process should participants wish to develop and delivery an actual online course.

To enhance the mobile accessibility of the course, mobile versions of the module presentations were made available that participants could view on their mobile device. In addition, through the use of best practices for mobile learning design, that course was accessible via the Blackboard Mobile Learn app on iOS or Android (see Fig. 4). This meant that participants could access the self-paced module presentations, online discussions, and other activities from any smart phone or tablet.

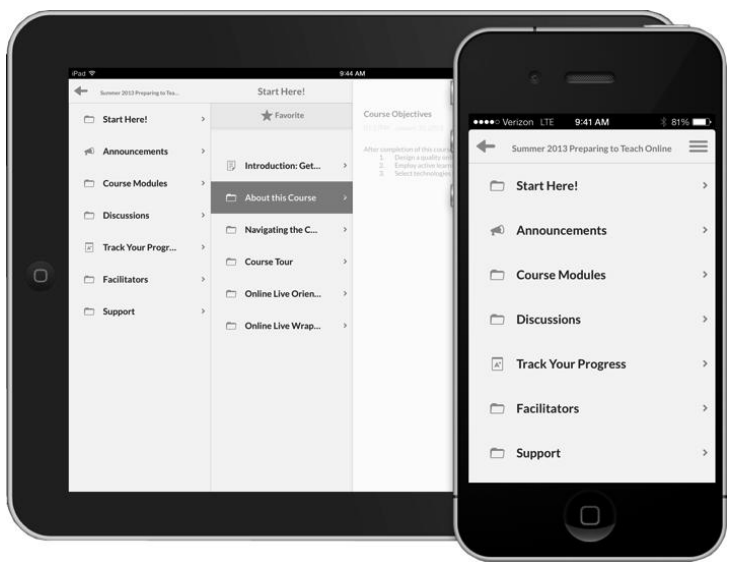

Fig. 4. Accessing Blackboard course on smart phone and tablet.

\section{E. Design and Development Process}

The extensive design and development process involved not only the creation of the module content but also the online learning environment within the institution's learning management system in which faculty participants would be 
able to access the modules. The project team researched online teaching preparedness best practices and selected the topics to be covered. Once topics were identified, module presentations were outlined and storyboards were created to visualize what each module presentation would contain. Next, presentation narration scripts were written and reviewed and then audio narration was recorded and presentations produced. In conjunction with the presentation development activities, the accompanying online activities, discussions, and quiz questions were developed.

Once the module presentations were produced, the online course environment where they were to be housed needed to be built. The online course construction included building the module delivery structure in Blackboard and uploading and embedding the online presentations. Hyperlinks were added to presentation transcripts and mobile presentation files as well as supplemental online resources in each module. Online discussion forums and online quizzes were built in Blackboard and links added to the corresponding module folders. Additional custom configurations were made in developing the Blackboard course, such as creating adaptive release rules to sequence the availability of the modules and related activities, in an effort to build an optimal self-paced online learning experiences for NIU faculty.

\section{F. Review Process and Feedback}

The project development methods involved rigorous software engineering methods for designing, development, implementing, testing, and publishing the self-paced training modules on online teaching. The review process included intensive and detailed internal reviews from all FDIDC staff, reviews from select NIU faculty with expertise and previous experience in online teaching, as well as external reviews from select outside experts in the field of online teaching and learning. The modules were critically reviewed and rated using a course design rubric that assisted in improving the quality and content of the modules.

After implementing feedback from the initial internal and external reviews, FDIDC invited a small cohort comprised of 25 NIU faculty members to complete the self-paced modules during a pilot conducted June 2013. Faculty participants attended a synchronous online kick-off session where the project team provided an overview and introduction to the modules as well as answered any participants' questions. The session was recorded and made available for those participants who could not attend or wished to review later. Participants were then given four weeks to complete the self-paced modules and provide feedback on their experience to the project team. Participants were invited to a synchronous online wrap-up session to further discuss module content, ask questions, and learn about additional resources and next steps for designing an online course.

Of the 25 faculty participants, 16 completed all the modules and the final design document activity. Of the 16 who completed the modules, the project team received evaluations from all but one faculty member. Aside from discovering and addressing minor design and development errors in the modules, the overall feedback received was extremely positive. A number of faculty participants who reviewed the modules shared positive feedback, such as:
"I am very impressed with the course overall and enjoyed working through it. I know how much work it is to put something like this together and implement it effectively."

"Overall, this is an excellent self-paced training course. The structure of the course is concise and consistent. The course provides great presentations and supplemental materials on designing a quality online course."

After the initial pilot offering of the self-paced modules, the project team was able to further improve the quality of the modules based on the feedback received from the participants.

\section{G. Benefits}

The self-paced modules are envisioned to become a vital part of the comprehensive online teaching support development underway at NIU. The project team is hopeful that, by offering this comprehensive training, academic departments will be able to recruit more faculty members to teach online and therefore increase capacity for offered online programs. Additionally, it is anticipated that current and future faculty members will be trained more quickly on online teaching than the current approach to training them through costly fixed training programs. It is ultimately hoped that these efforts will expand NIU's regional and global presence through more online course and program offerings.

\section{RECOMMENDATIONS FOR SELF-PACED TRAINING DEVELOPMENT}

Based on the experience developing self-paced online training modules for preparing faculty to teach online at NIU, a number of recommendations are offered for faculty development staff to follow in developing self-paced faculty training. The recommendations fall into three categories: Planning Self-Paced Training, Developing Self-Paced Training, and Evaluating Self-Paced Training. These recommendations are summarized in Table I and listed in the sequence in which they are ideally implemented. The recommended steps are further discussed below to further explain their application.

\section{A. Planning Self-Paced Training}

Before embarking on the task of developing self-paced training, first review existing training and support that may already be available from outside the institution. Despite the previously mentioned benefits that do exist to develop institution-specific training and support, there may be pre-existing training programs and resources that will meet identified needs and can be implemented. When comparing the licensing costs for adopting existing self-paced training materials to the costs associated with developing custom training, the savings realized from adopting existing training and resources may outweigh the benefits of custom development.

After reviewing existing training options to become aware of what potential traiing and resources already exist, identify the needs and desired competencies of the faculty. It is through this analysis of existing faculty needs and identification of the desired faculty competencies to be achieved, that the scope of the training will begin to be 
conceptualized. This needs analysis phase will clarify the goals and range of outcomes that the training should help achieve.

TABLE I: RECOMMENDATIONS FOR SELF-PACED TRAINING DEVELOPMENT

\begin{tabular}{ll}
\hline \hline Planning Self-Paced & Review existing available faculty training and \\
Training & support
\end{tabular}

Identify faculty needs and desired competencies

Determine available personnel, resource, and timeframe for development

Specify technical characteristics

Clarify parameters for progress and completion, noting how activities scaffold

Decide how training will be compartmentalized and presented

Determine interaction

Write measurable outcomes for the training, then objectives for each component

Plan assessments

Set goals for development milestones and markers

\begin{tabular}{ll}
\hline $\begin{array}{l}\text { Developing } \\
\text { Self-Paced Training }\end{array}$ & \begin{tabular}{l} 
Sequence content delivery and activities \\
Decide on required and optional activities and \\
resources \\
\\
Create a prototype to evaluate delivery format \\
\\
$\begin{array}{l}\text { Ensure accessibility } \\
\text { Invite experts to review and provide suggestions } \\
\text { for improvement } \\
\text { Pilot test implementation with small group and } \\
\text { collect feedback }\end{array}$ \\
\hline $\begin{array}{l}\text { Survey participants upon completion to measure } \\
\text { their reaction and learning } \\
\text { Training }\end{array}$ \\
Analyze module analytics for usage patterns \\
Follow-up with participants over time to gauge \\
change in their practices
\end{tabular} \\
\hline \hline
\end{tabular}

In conjunction with identifying the desired outcomes, determine available personnel, resources, and the timeframe for development. Before committing to developing training, ensure that the necessary staff and financial resources are available to complete the development in the required period of time. Staff with instructional design, graphic design, multimedia development, and Web development skills may be needed as well as hardware and software for development.

Once it has been determined that necessary resources and personnel are available and a development timeframe established, the next phase of planning efforts can commence. Begin by specifying the technical characteristics of the desired training. Given the self-paced nature of the training, how will it be deployed to participants? On what devices and software platforms will the training be accessible from? Does access need to be restricted to select users? Does completion need to be tracked and if so, how? These are just a few of the technical characteristics that should be specified to guide the planning efforts further.

Closely related to the technical characteristics are the facets of the envisioned user experience. Clarify the parameters for progress and completion of the desired self-paced training, noting how activities scaffold. Consider how content and activities should be sequenced in determining which module should be completed before proceeding to another.

When considering topic sequence, decide how the training will be compartmentalized and presented. Select a structured and consistent delivery format, such as modules or units, and decide what standard components will be included in each training segment. Beyond the content to be presented, consider what additional resources and activities would be beneficial to include.

Also, determine what interaction is desired throughout the self-paced training. As the participants complete the training at their own pace, how and to what level will participants interact with the content, facilitator(s), and other participants? Planning for engaging and meaningful interaction throughout the training where participants feel connected and supported will distinguish a well-designed self-paced training experience from merely a collection of tutorials.

With the technical parameters and overarching scope and sequence of the training established, efforts can then focus on further planning the specifics of the content and activities to be developed. Write measurable outcomes for the training, with objectives for each segment. Ensuring that clear and measurable objectives are established is foundational to remaining planning and development efforts, as all content and associated activities should align to one or more instructional objectives.

Next, plan activities and assessments to be included in the self-paced training that offer participants the opportunity to demonstrate that instructional objectives have been met. How might participants apply the concepts from the content into a real-world scenario? Assessments might consist of a combination of automated response objective assessments along with more subjective and authentic assessment types, where feedback is provided and remaining questions are answered.

In concluding the planning phase, set goals for development milestones and markers for the development team to follow. With the desired development timeframe in mind, consider the various milestones that will need to be met and at what intervals deadlines will need to be met. After doing so, the development phase is ready to begin.

\section{B. Developing Self-Paced Training}

With the previously described planning steps completed, sequence the content delivery and activities to meet the established training structure. This development task, while time consuming, is important for ensuring that the content and activities developed complement each other and support the desired learning outcomes.

As content and activities are being sequenced, decide on required and optional activities and resources. Providing a balanced mix of required and supplemental content and activities allows participants to self-direct their learning experience and engage in deeper exploration where desired.

After sequencing content and activities, create a prototype of the module structure and content to evaluate the delivery format. In doing so, technical issues can be resolved and presentation delivery further refined in advance of production. Once the prototype module has been reviewed and any necessary revisions have been verified, the development team can replicate the approved delivery mode across all modules 
during development and production.

Throughout the development and production process, it is essential to ensure accessibility of all materials and activities. For example, if developing instructional presentations and tutorials, write narration scripts and include transcripts in an easily accessible format. Also consider the device platforms participants will use to access the training and test the training on as many different potential platforms as possible.

Once the initial iteration of the training is developed, invite experts to review and provide suggestions for improvement. Several phases of expert review could be incorporated, involving reviewers both internal and external to the institution. If possible, pilot test the training implementation with a small group of faculty and collect feedback and continually seek to incorporate revisions where necessary. A thorough and ongoing review process will help ensure the best possible self-paced training experience for faculty.

\section{Evaluating Self-Paced Training}

Essential to the design, development, and implementation of any training program is a systematic process for evaluating the effectiveness and impact of the initiative. While often conducted at the conclusion of a training program or thereafter, evaluation can take many different forms and be conducted in countless ways. At its core, evaluation is the mechanism by which the existence of the training initiave can be justified and information gathered for how to improve future iterations of the offering. Evaluation can assess training on multiple levels, ranging from reaction and learning to behavior and results [21]. With such information collected, decisions can then be made regarding enhancements to the training components as well as the overall program impact can be validated.

A variety of evaluation measures are recommended to incorporate into the training program process. First, survey participants immediately upon completion to measure their reaction and learning. While the experience is still fresh in participants' mind, ask them to complete a brief survey to provide feedback on their experience completing the training, what were the most valued takeaways, what specific elements were most helpful, and suggestions for how the training might be improved in the future. Create a brief survey that includes a mix of objective as well as open-ended questions using an online survey tool and provide the link at the conclusion of training for participants to complete. Provide instructions and remind the participants to complete, thanking them for their participation and feedback. After all participants have completed, review the automatically compiled results for overall reactions and trends.

Along with surveying participants, analyze any available training module analytics for usage patterns that can provide greater insights into how the training components were used. Depending on the deployment system, a number of different analytics may be available, including number of hits per user, click-throughs, and length of each media item viewed. Further exploring statistics such as date and time completed, attempts per day, as well as the sequence of resources accessed can provide helpful indicators for what coomponents participants may have found most helpful, viewed multiple times, or perhaps skipped altogether. Additionally, examine performance on completed assessments to look for questions that were commonly missed, indicating training points that perhaps can be refined or better explained in future iterations.

The ultimate evaluation metrics provide in broad scope to administration and stakeholders the behavior change and resulting impact to participants from having completed the training. In seeking to measure these overall results, follow-up with participants over time to gauge the impact that the training has had on their practices. Pick a timeframe in which participants should have ample opportunity to begin implementing the new knowledge or skills acquired through the training and then follow-up with the participants at that time to learn how their methods may have been impacted. Provide a brief follow-up survey for participants to share how they were able to apply what they learned through the training into their practices and if possible, what perceived impact their new methods have made.

\section{CONCLUSION}

As institutions strive to develop new online programs and build online instructional capacity, a growing number of faculty need to be trained and equipped to teach online. While Faculty Development and Teaching and Learning centers have employed a variety of delivery modalities for online teaching training and support, self-paced models for online training offer many benefits and have been effectively implemented in a variety of online training contexts. The Faculty Development and Instructional Design Center at Northern Illinois University has developed a self-paced model for preparing faculty to teach online that provides a flexible and customizable option for faculty training and support that can be replicated. Following recommendations for systematic planning design, development and implementation, the self-paced model can be replicated by institutions seeking to prepare faculty to teach online.

\section{ACKNOWLEDGMENT}

The authors would like to express their sincere gratitude to the NIU Foundation, staff of Faculty Development and Instructional Design Center, and the Office of the Provost at Northern Illinois University for their support and contributions to the authors' online self-paced training research and experience.

\section{REFERENCES}

[1] K. Higgins and R. E. Harreveld, "Professional development and the university casual academic: Integration and support strategies for distance education," Distance Education, vol. 34, no. 2, pp. 189-203, 2013.

[2] J. Gregory and G. Salmon, "Professional development for online university teaching," Distance Education, vol. 34, no. 3, pp. 256-270 2013.

[3] V. Diaz, P. B. Garrett, E. R. Kinley, J. F. Moore, C. M. Schwartz, and P. Kohrman, "Faculty development for the $21^{\text {st }}$ century," Educause Review, vol. 33, no. 3, pp. 46-55, 2009.

[4] I. E. Allen and J. Seaman, Grade Change: Tracking Online Education in the United States, Babson Survey Research Group, 2014.

[5] National Center for Education Statistics. (2013). Enrollment in Distance Education Course, by State: Fall 2012. [Online]. Available: http://nces.ed.gov/pubsearch/pubsinfo.asp?pubid=2014023

[6] I. E. Allen and J. Seaman, Changing Course: Ten Years of Tracking Online Education in the United States, Babson Survey Research Group, 2013. 
[7] M. Edwards, B. Perry, and K. Janzen, "The making of an exemplary online educator," Distance Education, vol. 32, no. 1, pp. 101-118, Winter 2011.

[8] K. Lackey, "Faculty development: An analysis of current and effective training strategies for preparing faculty to teach online," Online Journal of Distance Learning Administration, vol. 14, no. 4, 2011.

[9] J. McClary, "Factors in high quality distance learning courses," Online Journal of Distance Learning Administration, vol. 16, no. 2, Summer 2013.

[10] M. Britto, C. Ford, and J.-M. Wise, "Three institutions, three approaches, one goal: Addressing quality assurance in online learning," Journal of Asynchronous Learning Networks, vol. 14, no. 4, February 2014.

[11] K. A. Meyer and V. S. Murrell, "A national study of training content and activities for faculty development for online teaching," Journal of Asynchronous Learning Networks, vol. 18, no. 1, April 2014.

[12] B. Riedlinger and P. Rosenberg, "Uniting technology and pedagogy: The evolution of an online teaching certification course," Educause Quarterly, no. 1, January 2006.

[13] Online Learning Consortium. [Online]. Available: http://www.onlinelearningconsortium.org

[14] Learning Resources Network. [Online]. Available: http://www.lern.org

[15] Illinois Online Network. [Online]. Available: http://www.ion.uillinois.edu

[16] University of Wisconsin-Madison. Professional Certificate in Online Education. [Online]. Available: http://continuingstudies.wisc.edu/distance-education/pcoe.html

[17] University of Michigan-Flint. Online Instructor Certificate Program. [Online]. Available: http://umflint.edu/oel/professional-development-online-instructor-cert ificate

[18] J. Rhode, "Interaction equivalency in self-paced online learning environments: An exploration of learner preferences," The International Review of Research in Open and Distance Learning, vol. 10, no. 1, February 2009

[19] L. May, K. Acquaviva, A. Dorfman, and L. Posey, "Medical student perceptions of self-paced, web-based electives: A descriptive study," American Journal of Distance Education, vol. 23, no. 4, pp. 212-223, 2009.

[20] M. Russell, G. Kleiman, R. Carey, and J. Douglas, "Comparing self-paced and cohort-based online courses for teachers," Journal of Research on Technology in Education, vol. 41, no. 4, 2009.
[21] D. L. Kirkpatrick, Evaluating Training Programs, 2nd ed., San Francisco, CA: Berrett-Koehler, 1998, pp. 3-18.

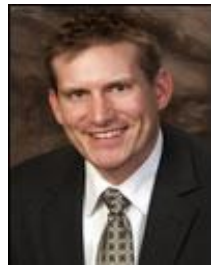

Jason Rhode received his bachelor's degree in children's ministries in 2000 from North Central University, the master's degree in curriculum and instruction in 2003 from Seattle Pacific University, and a doctorate in instructional design for online learning from Capella University in 2008.

$\mathrm{He}$ is the director of the Faculty Development and Instructional Design Center at Northern Illinois University in DeKalb, Illinois, U.S.A. His research interests include online learning, instructional design, faculty development, learning management systems, social learning, and online teaching.

Dr. Rhode is a member of the Professional and Organizational Development (POD) Network, Online Learning Consortium, and the Supporting Learning and Technology in Education (SLATE) Group. He has received numerous online teaching awards, including the recent 2014 Blackboard Catalyst Award for Exemplary Course Design, 2013 Blackboard Key to the Community award, and was named a Blackboard MVP. He is also the recipient of the 2012 NIU Supportive Professional Staff Presidential Award for Excellence.

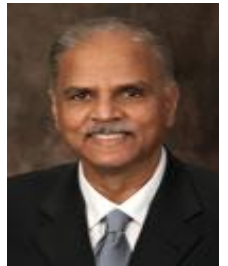

Murali Krishnamurthi received a bachelor's degree in mechanical engineering in 1978 from University of Madras, a master's degree in industrial and systems engineering in 1982 from Ohio University, and a doctorate in industrial engineering in 1988 from Texas A\&M University.

$\mathrm{He}$ is a professor of industrial and systems engineering and acting vice provost for faculty affairs at Northern Illinois University in DeKalb, Illinois, U.S.A. His teaching and research interests include project management, information systems, system simulation, optimization techniques, faculty development, and distance learning.

Dr. Krishnamurthi is a member of the American Association for Engineering Education (ASEE) and the Professional and Organizational Development (POD) Network. In 2011, he received the Presidential Teaching Professor Award and the Deacon Davis Diversity Award at Northern Illinos University. 